\title{
Facial profile esthetics in operated children with bilateral cleft lip and palate
}

\author{
Rita de Cássia Moura Carvalho Lauris¹, Leopoldino Capelozza Filho², Louise Resti Calil, \\ José Roberto Pereira Lauris³, Guilherme Janson³, Daniela Gamba Garib¹
}

DOI: https://doi.org/10.1590/2177-6709.22.4.041-046.oar

Objective: The aim of this study was to evaluate the facial profile esthetics of rehabilitated children with complete bilateral cleft lip and palate (BCLP), comparing the judgment of professionals related and not related to cleft rehabilitation and laypersons. Methods: Thirty children in the mixed dentition ( 24 male; 6 female) with a mean age of 7.8 years were evaluated using facial profile photographs by 25 examiners: 5 orthodontists and 5 plastic surgeons with experience in cleft care, 5 orthodontists and 5 plastic surgeons without experience in oral cleft rehabilitation and 5 graduated laymen. Their facial profiles were classified into esthetically unpleasant (grade 1 to 3), esthetically acceptable (grade 4 to 6), and esthetically pleasant (grade 7 to 9). Intraexaminer and interexaminer errors were evaluated using Spearman correlation coefficient and Kendall's test, respectively. Inter-rater differences were analyzed using Friedman test and Student-Newman-Keuls test for multiple comparisons. Results: Orthodontists dealing with oral clefts rehabilitation considered the majority of the sample as esthetically pleasant. Plastic surgeons of the cleft team and laypersons classified most of the sample as esthetically acceptable. Most of the orthodontists and plastic surgeons not related to cleft care evaluated the facial profile as esthetically unpleasant. The structures associated to unpleasant profiles were the nose, the midface and the upper lip. Conclusions: The facial profile of children with BCLP was classified as esthetically acceptable by laypersons. Professionals related to cleft rehabilitation were more lenient and those not related to cleft care were stricter to facial esthetics than laypersons.

Keywords: Cleft lip. Cleft palate. Esthetics. Rehabilitation.

\begin{abstract}
Objetivo: o objetivo desse estudo foi avaliar a estética do perfil facial de crianças com fissura labiopalatina completa bilateral (FLCB) operadas, comparando o julgamento de leigos e de profissionais relacionados e não relacionados à reabilitação de fissuras. Métodos: fotografias do perfil facial de trinta crianças na dentadura mista (24 do sexo masculino e 6 do sexo feminino), com idade média de 7,8 anos, foram avaliadas por 25 examinadores: 5 ortodontistas e 5 cirurgiões plásticos com experiência em fissuras, 5 ortodontistas e 5 cirurgiões plásticos sem experiência na reabilitação de fissuras, e 5 leigos com formação superior. Os perfis faciais foram classificados como esteticamente desagradável (grau 1 a 3), esteticamente aceitável (grau 4 a 6) e esteticamente agradável (grau 7 a 9). Para verificar a concordância intraexaminadores e interexaminadores, foram utilizados o Coeficiente de Correlação de Spearman e o Coeficiente de Concordância de Kendall, respectivamente. Para comparação entre as categorias de acordo com os escores atribuídos, foram aplicados o teste de Friedman e o teste de Student-Newman-Keuls, para comparações múltiplas. Resultados: os ortodontistas que lidam com reabilitação de fissuras labiopalatinas consideraram a maioria da amostra como esteticamente agradável. Cirurgiões plásticos com experiência em fissuras e leigos classificaram a maioria da amostra como esteticamente aceitável. Grande parte dos ortodontistas e cirurgiões plásticos sem experiência na reabilitação de fissuras classificou o perfil facial como esteticamente desagradável. As estruturas associadas aos perfis desagradáveis foram o nariz, o terço médio da face e o lábio superior. Conclusões: o perfil facial de crianças com FLCB foi classificado como esteticamente aceitável pelos leigos; já os profissionais relacionados à reabilitação de fissuras foram mais complacentes, em comparação aos profissionais sem experiência na reabilitação de fissuras, que, por sua vez, foram mais rigorosos quanto à estética facial do que os leigos.
\end{abstract}

Palavras-chave: Fenda labial. Fissura palatina. Estética. Reabilitação.

\footnotetext{
${ }^{1}$ Universidade de São Paulo, Hospital de Reabilitação de Anomalias Craniofaciais, Departamento de Ortodontia (Bauru/SP, Brasil).

${ }^{2}$ Universidade do Sagrado Coração, Programa de Pós-graduação em Ortodontia, Departamento de Biologia Oral (Bauru/SP, Brasil).

${ }^{3}$ Universidade de São Paulo, Faculdade de Odontologia de Bauru,

Departamento de Ortodontia (Bauru/SP, Brasil).
}

» The authors report no commercial, proprietary or financial interest in the products or companies described in this article.

» Patients displayed in this article previously approved the use of their facial and intraoral photographs.

\begin{abstract}
How to cite: Lauris RCMC, Capelozza Filho L, Calil LR, Lauris JRP, Janson G, Garib DG. Facial profile esthetics in operated children with bilateral cleft lip and palate. Dental Press J Orthod. 2017 July-Aug;22(4):41-6. DOI: https://doi.org/10.1590/2177-6709.22.4.041-046.oar
\end{abstract}

Submitted: April 20, 2016 - Revised and accepted: April 18, 2017

Contact address: Louise Resti Calil

Faculdade de Odontologia de Bauru, Universidade de São Paulo Alameda Octávio Pinheiro Brisolla, 9-75

Bauru/SP, Brasil - CEP: 17.012-901 -E-mail: louise.rc@hotmail.com 


\section{INTRODUCTION}

Complete bilateral cleft lip and palate (BCLP) is the most severe manifestation of oral clefts, corresponding to $14 \%$ of all types of oral clefts. ${ }^{1}$ BCLP causes serious esthetical, functional, anatomic and psychosocial disorders requiring early surgery repair. ${ }^{2}$ The rehabilitation protocol for BCLP includes lip and palate repair, alveolar bone graft and orthodontics, isolated or combined with orthognatic surgery. ${ }^{3}$ At birth, a patient with complete BCLP presents severe convex facial profile due to premaxilla projection. ${ }^{4}$ After lip repair, protrusion of the premaxilla decreases and maxillary deficiency may be observed during growth. ${ }^{5}$ According to Semb, ${ }^{5}$ in patients with BCLP, the maxilla is prominent at 5 years of age. At 7 years of age the maxillary prominence is similar to individuals without cleft. At 18 years of age, the maxilla shows severe retrusion. Maxillary growth deficiency decreases facial convexity in BCLP. Additionally, patients with BCLP show hyperdivergent growth of the mandible determining a posteriorly positioned chin. ${ }^{3}$

In patients with BCLP, besides the maxillary deficiency, the upper lip scar, columella length and nasal morphology may impair facial esthetics. ${ }^{6-9}$ In the few studies that judged facial esthetics of patients with oral clefts, there is consensus regarding the dissatisfaction with the cosmetic results obtained by the professionals involved in their rehabilitation, as well as by the patients themselves. ${ }^{10,11}$ Chetpakdeechit et $\mathrm{al}^{12}$ analyzed the facial esthetic outcome of patients with BCLP after orthodontic treatment and found that the upper lip, the nose and the scar were negative features affecting the esthetical evaluation. A recent study has evaluated the facial profile esthetics of BCLP after complete rehabilitation and classified most of the sample as esthetically acceptable. ${ }^{13}$

Evaluation of facial esthetics is extremely important in order to study the outcome of treatment protocols. ${ }^{1}$ The main goals of rehabilitation is reaching good facial esthetics and speech intelligibility. ${ }^{11}$ The few previous studies on facial esthetics evaluation in CLP were performed in adulthood after complete rehabilitation. ${ }^{11-16}$ However, facial appearance in the school age is very important for children interrelationship, sociability, self-esteem and learning productivity. ${ }^{17-19}$ Therefore, the aim of this study was to evaluate the esthetics of facial profile in children with complete BCLP and compare the assessment of laypersons and professionals related and not related to cleft rehabilitation.

\section{MATERIAL AND METHODS}

This cross-sectional study was approved by the Ethical Committee of our institutional review board (protocol number 438/2002) and an informed consent was obtained. The study sample comprised 30 children in the mixed dentition with complete BCLP consecutively selected during the year of 2004 at a single center. The selection was performed during the first orthodontic appointment. The inclusion criteria were: Mediterranean descents and absence of syndromes. The sample included 24 males and 6 females with a mean age of 7.8 years of age (ranging from 5.6 to 10.3 years).

All patients were operated by a plastic surgeon of Hospital de Reabilitação de Anomalias Craniofaciais team following the current protocol of the hospital which includes one-stage lip repair with Spina technique at 3 to 6 months of age and palate repair with Von Langenback technique at 12 months of age. No presurgical orthopedics was used. In most cases, nasal columella elongation was performed at 6.3 years of age on average. The evaluation was performed before secondary bone graft procedure.

The photographs were taken by the same examiner using a natural head position. ${ }^{20,21}$ Patients were instructed to have the teeth occluded and the lips relaxed.

Right and left facial profile photographs were taken from each patient. The obtained images were transferred to a computer and printed in a $10 \times 15 \mathrm{~cm}$ size. The photographs were evaluated by twenty-five examiners divided into five groups: 5 orthodontists with experience in rehabilitation of oral clefts (ODC), 5 orthodontists with no experience in cleft treatment (ONC), 5 plastic surgeons with experience in oral clefts (PSDC), 5 plastic surgeons with no experience in cleft treatment (PSNC) and 5 laypersons (1 veterinarian, 1 engineer, 2 lawyers and 1 agronomist). All the professionals with experience in oral clefts worked at the center where the study was conducted.

Each examiner received an album with the sample of 60 photographs. Both facial profiles of each patient 
were positioned in the same page for simultaneous visualization. No identification of the presence of cleft was provided. The raters were instructed to perform the assessment within approximately 30 seconds for each photograph, assigning scores from 1 to 9 according to Ferrari Jr. et al. ${ }^{13}$

Facial profile was considered esthetically unpleasant for scores 1 to 3; esthetically acceptable for scores 4 to 6 , and esthetically pleasant for scores 7 to 9 (Figs 1 to 3, respectively). When the score assigned was 1 to 3 , the examiner was requested to identify the facial structures responsible for the unpleasant aspect. The photographs were evaluated twice by the 25 examiners with an interval of 30 days between both evaluations.

\section{Method error}

Intraexaminer errors were evaluated using Spearman correlation coefficient. Interexaminer error was evaluated using Kendall Coefficient of Agreement (W).

\section{Statistical analyses}

Inter-rater differences were compared using Friedman test and Student-Newman-Keuls test for multiple comparisons. The significance level regarded was 5\%.

\section{RESULTS}

Intraexaminer agreement was statistically significant for all the rater categories and the coefficient of agreement varied from 0.46 to 0.68 (Table 1). There was statistically significant interexaminer agreement within all categories of raters and the coefficient of agreement varied from 0.55 to 0.74 (Table 2).

There were significant differences among all rater categories except between ONC and PSNC. The ODC and PSDC assigned the highest scores for facial esthetics compared to the other raters (Table 3). ONC and PSNC assigned the lowest scores. Laymen gave intermediate scores between professionals related and non related to cleft care.

The frequency of "esthetically unpleasant" scores was very low for ODC and PSDC (Table 4). In contrast, ONC and PSNC classified more than $50 \%$ of the sample as having unpleasant profiles.

The structures most frequently pointed as responsible for the unpleasant profile were the nose and the midface (Fig 4).

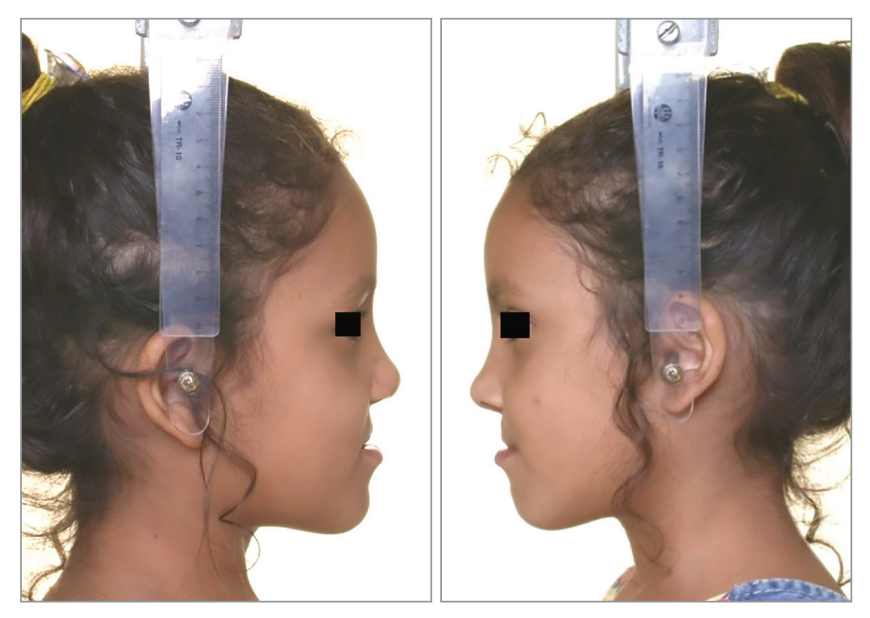

Figure 1 - Patient who obtained the lowest score (2.8).
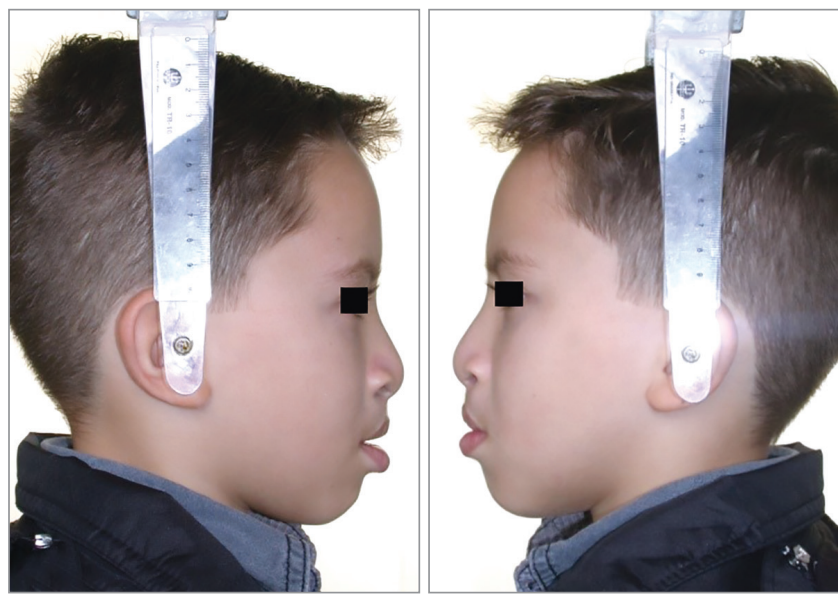

Figure 2 - Patient who obtained an intermediate score (4.4).
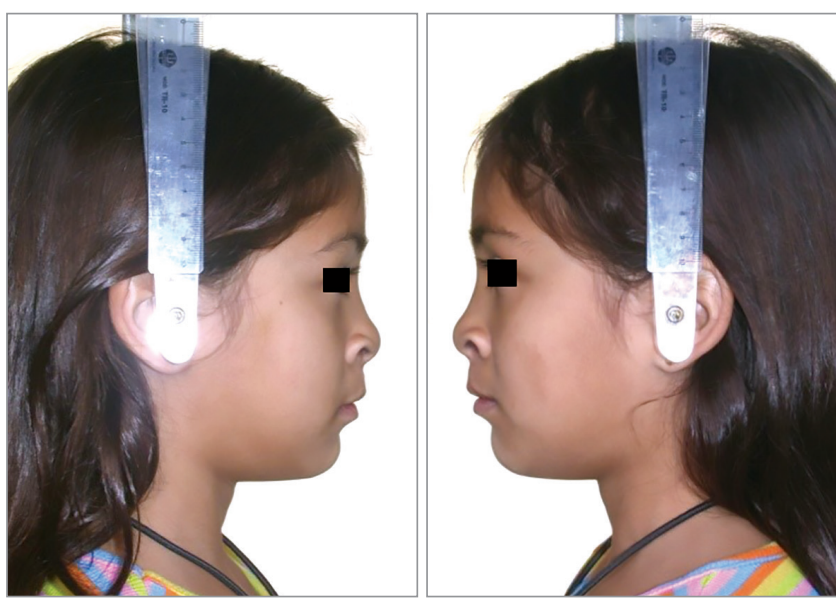

Figure 3 - Patient who obtained the highest score (6.2). 
Table 1 - Intraexaminer agreement for each category of raters (Spearman correlation coefficient).

\begin{tabular}{ccc}
\hline Category & $\boldsymbol{r}_{\mathrm{s}}$ & $\boldsymbol{p}$ \\
\hline ODC & 0.63 & $0.0001^{*}$ \\
\hline ONC & 0.68 & $0.0001^{*}$ \\
\hline PSDC & 0.56 & $0.0001^{*}$ \\
\hline PSNC & 0.46 & $0.0001^{*}$ \\
\hline$L$ & 0.51 & $0.0001^{*}$ \\
\hline
\end{tabular}

*Statistically significant at $p<0.05$

ODC: orthodontists dealing with cleft; ONC: orthodontists with no experience in cleft; PSDC: plastic surgeons dealing with cleft; PSNC: plastic surgeons with no experience in cleft; L: laymen.
Table 2 - Interexaminer agreement for each category of raters (Kendall's coefficient of agreement)

\begin{tabular}{ccc}
\hline Category & W & $p$ \\
\hline ODC & 0.74 & $0.0001^{*}$ \\
ONC & 0.64 & $0.0001^{*}$ \\
\hline PSDC & 0.57 & $0.0001^{*}$ \\
\hline PSNC & 0.64 & $0.0001^{*}$ \\
\hline$L$ & 0.55 & $0.0001^{*}$ \\
\hline
\end{tabular}

*Statistically significant at $p<0.05$

ODC: orthodontists dealing with cleft; ONC: orthodontists with no experience in cleft; PSDC: plastic surgeons dealing with cleft; PSNC: plastic surgeons with no experience in cleft; L: laymen.

Table 3 - Interexaminer comparisons for scores of facial profile esthetics (Friedman and Student-Newman-Keuls tests)

\begin{tabular}{cccccc}
\hline ODC & ONC & PSDC & PSNC & L \\
Mean (SD) & Mean (SD) & Mean (SD) & Mean (SD) & Mean (SD) \\
\hline $6.4(0.61)^{\mathrm{a}}$ & $3.2(0.74)^{\mathrm{b}}$ & $5.1(0.99)^{\mathrm{c}}$ & $3.2(0.26)^{\mathrm{b}}$ & & $4.0(1.26)^{\mathrm{d}}$ \\
\hline
\end{tabular}

Different letters show statistically significant differences (Student-Newman-Keuls test)

ODC: orthodontists dealing with cleft; ONC: orthodontists with no experience in cleft; PSDC: plastic surgeons dealing with cleft; PSNC: plastic surgeons with no experience in cleft; L: laymen.

\section{DISCUSSION}

The concept of beauty is very subjective and varies individually. ${ }^{11}$ Despite the subjectivity of beauty interpretation, there was good intra and interexaminer agreement. ${ }^{11,13}$ Previous studies also showed good reproducibility of the subjective facial analysis method. ${ }^{11,13}$ Additionally, splitting the raters by category may have decreased the variation between them.

Differences for the evaluation of facial esthetics were observed for the different types of raters (Table 3). Orthodontists and plastic surgeons dealing with oral clefts (ODC and PSDC) scored most of the patients as esthetically acceptable even though the mean score was lower for the plastic surgeons. On the other hand, orthodontists and plastic surgeons not related to cleft care (ONC and PSNC) classified the facial profile of the sample as esthetically unpleasant. Laymen attributed an intermediate score between professionals related and not related to cleft care, considering the majority of the sample as esthetically acceptable. From the social point of view, layperson evaluation is more important because they represent the way society see the patient. The esthetics that pleases the patient's fellows has great significance in building selfesteem and inter-personal relationship. ${ }^{22}$ The layperson opinion is also very important considering the high frequency of bullying among patients with oral clefts. ${ }^{23,24}$
Table 4 - Percentage of patients classified as unpleasant by different category of raters.

\begin{tabular}{|cc}
\hline Category & $\%$ \\
\hline ODC & 3.30 \\
\hline ONC & 63.3 \\
\hline PSDC & 6.70 \\
\hline PSNC & 70.0 \\
\hline$L$ & 40.0 \\
\hline
\end{tabular}

ODC: orthodontists dealing with cleft; ONC: orthodontists with no experience in cleft; PSDC: plastic surgeons dealing with cleft; PSNC: plastic surgeons with no experience in cleft; L: laymen.

Why did professionals related to cleft care classified the sample with a much better score compared to laypersons? There was also a discrepancy between the frequency of esthetically unpleasant classification between professionals related to cleft care and laypersons (Table 4). While ODC and PSDC classified less than $10 \%$ of the sample as esthetically unpleasant, laymen scored $40 \%$ of the patients with the worse scores. Previous studies also verified that professionals related to cleft care were more lenient with facial esthetics at the end of the rehabilitation process. ${ }^{11,13}$ According to these studies, professionals dealing with cleft rehabilitation recognize the limitations of treatment and are more tolerant with morphologic deviations., 71,13 
Only one study found similarity in esthetic evaluation between plastic surgeons related to cleft care and laypersons, however the study considered only the nasal esthetic outcome of BCLP after secondary nasal reconstruction. ${ }^{25}$ Both raters considered the nose with acceptable esthetics even though far from the ideal. ${ }^{25}$

Professionals not constantly dealing with oral cleft rehabilitation have normality and perfection as comparative parameters and therefore are more strict in their evaluation. ${ }^{11}$ For this reason, they considered most of the profiles as esthetically unpleasant ( $\mathrm{Ta}-$ ble 4). This explains the deficient results compared to normality, which is also an important information for cleft care professionals.

Regarding the structures recognized as responsible for the lowest scores, the nose was the most cited for all categories of raters (Fig 4). The nose is largely affected by bilateral cleft lip and palate demonstrating a very short columella and a flat nose ala at birth. ${ }^{4}$ These results show the need for nose surgery in these patients, which is frequently performed at the end of the rehabilitation process, after growth. ${ }^{4}$ It is speculated that early plastic surgery of the nose could further impair maxillary growth and therefore it is postponed to the end of the rehabilitation process. The second and third structures most often cited as responsible for unpleasant profiles was the deficient midface and the retruded upper lip (Fig 4). Lip and palate repair cause progressive maxillary retrusion during growth, ${ }^{5}$ resulting in retruded midface and upper lip. These results show that maxillary growth deficiency can influence facial esthetics beginning at an early age. In summary, the structures that impair facial esthetic evaluation are those most affected by the cleft itself or by the primary interventions.

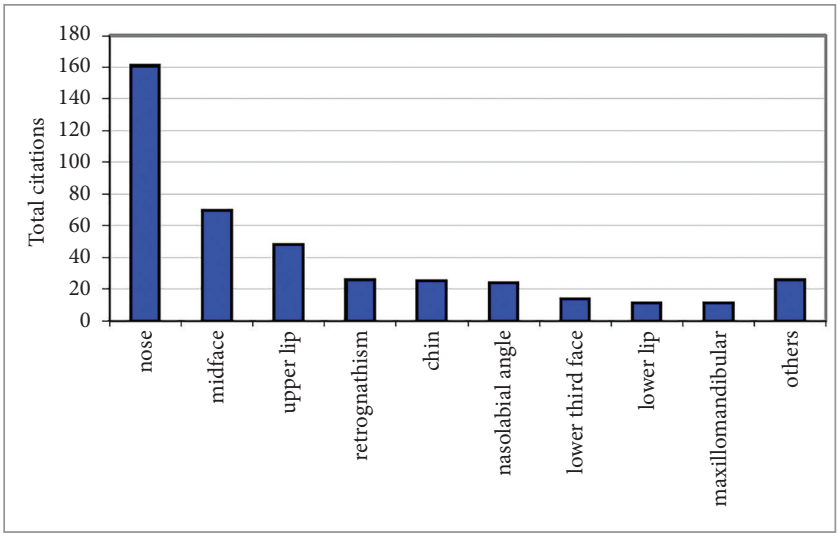

Figure 4 - The structures associated to the worst scores were the nose, the midface and the upper lip.

\section{CONCLUSIONS}

» The facial profile of rehabilitated children with complete BCLP was most frequently scored as esthetically acceptable.

" Professionals related to oral cleft rehabilitation gave better scores for facial esthetics than laypersons and professionals not related to cleft care.

\section{Author contributions}

Conception or design of the study: LCF. Data acquisition, analysis or interpretation: RCMCL, JRPL Writing the article: RCMCL, LCF, LRC, JRPL, GJ, DGG. Critical revision of the article: GJ, DGG. Final approval of the article: DGG. Obtained funding: RCMCL. 


\section{REFERENCES}

1. World Health Organization. Global strategies to reduce the health care burden of craniofacial anomalies: Report of $\mathrm{WHO}$ meetings on International Collaborative Research on Craniofacial Anomalies. Cleft Palate Craniof J. 2004 May:41(3):238-43

2. Garib DG, Santos PBD, Janson G, Assis VH, Battisti MPL. Association between dental arch widths and interarch relationships in children with operated unilateral complete cleft lip and palate. Cleft Palate Craniofac J. 2015 Nov; 52:e196-200.

3. Freitas JAS, Garib DG, Oliveira M, Lauris RCMC, Almeida ALPF, Neves LT, et al Rehabilitative treatment of cleft lip and palate: experience of the Hospital for Rehabilitation of Craniofacial Anomalies-USP (HRAC-USP)-Part 2: Pediatric Dentistry and Orthodontics. J Appl Oral Sci. 2012 Apr;20(2):272-85

4. Freitas JAS, Neves LT, Almeida ALPF, Garib DG, Trindade-Suedam IK, Yaedú RYF, et al. Rehabilitative treatment of cleft lip and palate: experience of the Hospital for Rehabilitation of Craniofacial Anomalies/USP (HRAC/USP)-Part 1: overall aspects. J Appl Oral Sci. 2012 Oct;20(1):9-15

5. Semb G. A study of facial growth in patients with bilateral cleft lip and palate treated by the Oslo CLP team. Cleft Palate Craniofac J. 1991 Jan;28(1):22-39.

6. Vargervik K. Growth characteristics of the premaxilla and orthodontic treatment principles in bilateral cleft lip and palate. Cleft Palate J. 1983 Oct:20(4):289-302.

7. Silva Filho OG, Valladares Neto J, Capelloza Filho L, Freitas JAS. Influence of lip repair on craniofacial morphology of patients with complete bilateral cleft lip and palate. Cleft Palate Craniofac J. 2003 Mar;40(2):144-53.

8. Tobiasen JM. Social judgments of facial deformity. Cleft Palate J. 1987 Oct;24(4):323-27.

9. Anderson SL, Adams G, Plaut VC. The cultural grounding of personal relationship: the importance of attractiveness in everyday life. J Pers Soc Psychol. 2008 Aug:95(2):352-68

10. Oosterkamp BC, Dijkstra PU, Remmelink HJ, van Oort RP, Goorhuis-Brouwer SM Sandham A, et al. Satisfaction with treatment outcome in bilateral cleft lip and palate patients. Int J Oral Maxillofac Surg. 2007 Oct; 36(10):890-5

11. Almeida AM, Capelozza Filho L, Ferrari Junior FM, Lauris RCMC, Garib DG Evaluation of facial esthetics in rehabilitated adults with complete unilateral cleft lip and palate: a comparison between professionals with and without experience in oral cleft rehabilitation. ISRN Plastic Surgery. 2013(2013):ID 357568, 7 pages.

12. Chetpakdeechit W, Wahss J, Woo T. Hugander M, Mohlin B, Hagberg C. Esthetic views on facial and dental appearance in young adults with treated bilateral cleft lip and palate (BCLP). A comparison between professional and non-professional evaluators. Swed Dent J. 2011;35(3):151-7.
13. Ferrari FM Júnior, Ayub PV, Capelozza Filho L, Pereira Lauris JR, Garib DG. Esthetic evaluation of the facial profile in rehabilitated adults with complete bilateral cleft lip and palate. J Oral Maxillofac Surg. 2015 Jan;73(1):169.e1-6.

14. Reis SAB, Abrão J, Capelozza Filho L, Claro CAA. Análise facial subjetiva. Rev Dental Press Ortod Ortop Facial. 2006 Set-Out;11(5):159-72

15. Noar JH. A questionnaire survey of attitudes and concerns of three professional groups involved in the cleft palate team. Cleft Palate Craniofac J. 1992 Jan;29(1):92-5

16. Starr P. Physical attractiveness and self-esteem ratings of young adults with cleft lip and/or palate. Psychol Rep. 1982 Apr;50(2):467-70.

17. Hunt O, Burden D, Hepper P. Stevenson M, Johnston C. Self-reports of psychosocial functioning among children and young adults with cleft lip and palate. Cleft Palate Craniofac J. 2006 Sept:43(5):598-605.

18. Tiemens K, Nicholas D, Forrest CR. Living with difference: experiences of adolescent girls with cleft lip and palate. Cleft Palate Craniofac J. 2013 Mar;50(2):e27-34.

19. Sharif MO, Callery P, Tierney S. The perspectives of children and young people living with cleft lip and palate: a review of qualitative literature. Cleft Palate Craniofac J. 2013 May:50(3):297-304

20. Cooke MS, Wei SH. The reproducibility of natural head posture: a methodological study. Am J Orthod Dentofacial Orthop. 1988 Apr;93(4):280-8.

21. Peng L, Cooke MS. Fifteen-year reproducibility of natural head posture: a longitudinal study. Am J Orthod Dentofacial Orthop. 1999 July;116(1):82-5.

22. Farkas LG, Kolar JC. Anthropometrics and art in the aesthetics of women's faces. Clin Plast Surg. 1987:14(4):599-616

23. Chetpakdeechit W, Hallberg U, Hagberg C, Mohlin B. Social life aspects of young adults with cleft lip and palate: grounded theory approach. Acta Odontol Scand. 2009 July:67(2):122-8.

24. Havstam C, Laakso K, Ringsberg KC. Making sense of the cleft young adults accounts of growing up with a cleft and deviant speech. J Health Psychol. 2011:16(1):22-30

25. Lo LJ, Wong FH, Chen YR, Lin WY, Ko EW. Palatal surface area measurement: comparisons among different cleft types. Ann Plast Surg. 2003 Jan;50(1):18-23; discussion 23-4. 